\title{
Method for assessing the energy efficiency of a vehicle taking into account the load under operating conditions
}

\author{
Umidulla Abdurazzokov ${ }^{*}$, Bakhramjan Sattivaldiev, Ravshan Khikmatov, and Shakhnoza \\ Ziyaeva
}

Tashkent State Transport University, Tashkent, Uzbekistan

\begin{abstract}
In operation conditions, the transport work of a vehicle is estimated by the increment in the mass of the freight over the distance traveled. This criterion does not characterize the mechanical work of the vehicle in the transport process. Without analyzing the energy costs of performing mechanical work, it is impossible to assess the energy efficiency of a vehicle.

The energy efficiency of a vehicle is defined as the ratio of the mechanical work performed by the vehicle to the potential energy of the source. In this paper, it is proposed to determine the engine torque by fuel consumption. The engine torque value depends on the energy required for driving the vehicle.

Based on the analysis of the results of computational and experimental studies, a method for assessing the energy efficiency of a vehicle with an internal combustion engine is proposed. The reliability of the results obtained is substantiated by the test results and the available information in practice.
\end{abstract}

\section{Introduction}

In the world, research has been carried out aimed at solving the problems of reducing transport costs $[1,4,8,17]$, efficient use of vehicle resources and operating materials [11, $12,15]$, ensuring environmental and road traffic safety $[2,3]$, operational control of the established normative indicators $[7,14,16]$, the energy efficiency of vehicle $[5,6,9,10$, 13]. The criteria and methods proposed in these studies for assessing the energy efficiency of vehicles do not fully take into account road loads and driving modes under operating conditions, which leads to low use of the structurally built potential of the structure and operating materials. Consequently, a study to improve the efficiency of using operational materials with the introduction of modern intelligent systems in determining the parameters of the movement of vehicles, to improve the criterion for assessing the energy efficiency of vehicles taking into account the load under operating conditions is relevant.

Purpose of the study: improvement of the method for assessing the energy efficiency

\footnotetext{
${ }^{*}$ Corresponding author: abdurazzoqovumid@gmail.com
} 
of a vehicle, taking into account the load under operating conditions.

Research objectives: to analyze the existing methods for assessing the energy efficiency of vehicles; to develop a criterion for assessing the energy efficiency of vehicles; to improve the method for assessing the energy efficiency of a vehicle taking into account the load under operating conditions

\section{Methods}

Based on the analysis of the studies, it was revealed that the current indicators of transport work, such as $t \cdot \mathrm{km}, \mathrm{km}$, do not fully take into account the load under operating conditions. In this regard, it is proposed to consider the mechanical energy of the vehicle, determined by the energy index $E[J]$, necessary to overcome the forces of resistance to movement during transportation and to assess the compliance with the parameters of real operating conditions.

When transported on a route, the vehicle operates in traction mode and deceleration/braking mode. The rest of the modes that characterize the typical mode of movement of the vehicle on the route are considered non-production. Based on this, the load on the structure is determined by the mechanical energy on the driving wheels of the vehicle and is described by the following formula:

$$
E=E_{A}+E_{A d}
$$

where $E_{A}, E_{A d}$ is mechanical energy, respectively, in traction mode and deceleration/braking mode, $J$.

Based on the provisions of the vehicle theory, the mechanical energy required to overcome the forces of resistance to the movement of the vehicle in traction mode can be described by the following formula

$$
E_{A}=\int_{S_{i}}^{S_{f}}\left(P_{i}+P_{\psi}+P_{a}\right) d S=\int_{t_{i}}^{t_{f}} N_{k} d t
$$

where $P_{i}, P_{\psi}, P_{a}$ are respectively, the resistance forces of inertia, road, and air, $N ; S_{k}, S_{i}$ are respectively, the final and initial distance traveled, $m ; t_{f}, t_{i}$ are respectively, the final and initial time of movement, $s$.

Power delivered to the driving wheels of the vehicle

$$
N_{k}=M_{k} \omega_{k}=\left(P_{i}+P_{\psi}+P_{a}\right) V_{v}
$$

Similarly, to determine the power realized on the driving wheels of a vehicle, it is required to determine the kinematic and dynamic parameters of the dependence $N_{k}=f\left(M_{k}\right.$, $\left.\omega_{k}\right)$.

The angular velocity on the driving wheels of the vehicle is determined by the wellknown formula

$$
\omega_{k}=\frac{V_{v}}{r_{k}}
$$

where $V_{v}$ is vehicle speed, $m / s ; r_{k}$ is rolling radius of driving wheels, $m$.

Using transmission ratios $U_{t r}$, a given vehicle, engine crankshaft angular velocity $\omega_{k}$ is determined by the following relationship

$$
\omega_{e}=\omega_{k} U_{\text {тр }}=\frac{V_{a} U_{t r}}{r_{k}}
$$


To date, the torque on the driving wheels of the car $M_{k}$ determined by an experimental method on a bench or using a dynamometer in road conditions [18].

The main parameter in ensuring the energy and environmental performance of automobile engines is the excess air ratio $\lambda$, and the range of ensuring reliable ignition of the fuel is $0.7-1.3$. The motor's high thermodynamic efficiency is achieved at $\lambda=[1-$ 1.1]; therefore, a high specific fuel consumption $g_{e}$ is achieved in this range. To ensure efficient operation of the catalytic converter on modern engines with a homogeneous mixture, $\lambda=1$. In diesel engines $\lambda=1$ is provided only near the torch, and the total volume can reach up to 1.7 . The remaining volume of the cylinder is filled with exhaust gases using a recirculation system, which increases the environmental friendliness of the engine. Based on this, it can be established that the torque of diesel engines does not depend on the amount of air but directly depends on fuel consumption. Under vehicle operating conditions, it is difficult to measure engine torque but can be indirectly determined through fuel consumption $M_{e}=f\left(Q_{s}\right)$.

According to the vehicle theory, the fuel consumption is determined by the formula

$$
Q_{s}=\frac{g_{e} N_{k}}{36 V_{v} \rho_{T}}=\frac{g_{e N} K_{\omega} K_{I} M_{e} U_{t r}}{36 r_{k} \rho_{T}},
$$

where $M_{e}$ is effective engine torque, $N m ; g_{e N}$ is specific fuel consumption of the engine at maximum power, $\mathrm{g} / \mathrm{kWh} ; K_{\omega}$ is coefficient taking into account the change in specific fuel consumption $g_{e}$ depending on the angular speed of the engine crankshaft $\omega_{e}$; $K_{I}$ is coefficient taking into account the change in specific fuel consumption $g_{e}$ depending on the degree of use of engine power $I ; U_{t r}$ is transmission ratio; $\rho_{T}$ is fuel density, $\mathrm{kg} / \mathrm{l}$.

Since at a constant angular speed of the crankshaft, the torque value remains constant depending on the external load, this value remains at one rotation of the crankshaft. Therefore, it will be expedient to determine the directional fuel consumption per rotation of the engine crankshaft in a given mode. To do this, you need to use the hourly fuel consumption

$$
G_{T}=g_{e} N_{e},
$$

hence the value of the hourly fuel consumption is determined for one rotation of the crankshaft as follows

$$
G_{n}=\frac{G_{T} \pi}{1800 \omega_{e}}
$$

Based on the provisions of the vehicle theory, arbitrarily setting the parameters of the driving conditions and load $V_{v}, m_{v}, j_{v}, \psi$ the following equations determine the forces of resistance to motion

$$
P_{i}=m_{v} j_{v} \delta ; P_{\psi}=m_{v} g \psi ; P_{a}=c_{e} V_{v}^{2}
$$

where $m_{v}$ is vehicle weight with cargo, $\mathrm{kg} ; j_{a}$ is vehicle acceleration, $\mathrm{m} / \mathrm{s}^{2} ; \delta$ is coefficient of accounting for rotating masses; $g$ is free fall acceleration, $m / s^{2} ; \psi$ is road drag coefficient; $c_{e}$ is body streamline factor, $\mathrm{Hs}^{2} / \mathrm{m}^{2}$.

From the theory of the vehicle, it is known that the sum of the resistance forces is equal to the tractive force on the driving wheels, which is described by the following formula 


$$
P_{k}=P_{i}+P_{\psi}+P_{a}=\frac{M_{k}}{r_{k}}
$$

respectively through the gear ratio $U_{t r}$ and transmission efficiency $\eta_{t r}$ a given vehicle, the engine torque is determined $M_{e}$

$$
M_{e}=\frac{M_{k}}{U_{t r} \eta_{t r}}=\frac{\left(m_{v}\left(j_{v} \delta+g \psi\right)+c_{e} V_{v}^{2}\right) r_{k}}{U_{t r} \eta_{t r}}
$$

Based on the data obtained, matrix arrays of fuel consumption and engine torque values corresponding to one rotation of the engine crankshaft are formed.

With an arbitrary choice of the values of the parameters of the driving conditions, it is necessary to take into account the operating range of the engine, with the boundary conditions for the angular speed of the crankshaft $\omega_{\max }$ and $\omega_{\min }$, as well as maximum engine torque $M_{\text {emax }}$. It is advisable to set such load parameters that would cover a large part of the engine's operating range.

Tables $1-4$ show the fuel consumption values $G_{n}$ and engine torque $M_{e}$ on the example of trucks ISUZU NQR71 and MAN TGS 26.400.

\section{Results and Discussion}

Analysis of tables - 1-4 shows that with an increase in kinematic and dynamic loads, fuel consumption $G_{n}$ and engine torque $M_{e}$ increase proportionally. The results in tables - 1-4 characterize the partial modes of engine operation depending on external loads.

Table.1. Matrix array of fuel consumption values $G_{n}$ at different load modes of operation ISUZU NQR71

\begin{tabular}{|c|c|c|c|c|c|}
\hline \multirow{2}{*}{$\overline{\boldsymbol{\omega}_{\boldsymbol{e}}}$} & \multicolumn{5}{|c|}{$\overline{\boldsymbol{G}_{\boldsymbol{a}}}-$ relative change in gross vehicle weight } \\
\cline { 2 - 6 } & $\mathbf{0 , 3 6 4}$ & $\mathbf{0 , 5 2 3}$ & $\mathbf{0 , 6 8 2}$ & $\mathbf{0 , 8 4 1}$ & $\mathbf{1 , 0 0 0}$ \\
\hline 0.19 & 0.019 & 0.024 & 0.029 & 0.033 & 0.082 \\
\hline 0.27 & 0.020 & 0.025 & 0.029 & 0.033 & 0.080 \\
\hline 0.35 & 0.021 & 0.026 & 0.031 & 0.034 & 0.080 \\
\hline 0.43 & 0.023 & 0.028 & 0.032 & 0.036 & 0.082 \\
\hline 0.51 & 0.026 & 0.030 & 0.034 & 0.037 & 0.086 \\
\hline 0.59 & 0.029 & 0.033 & 0.036 & 0.040 & 0.092 \\
\hline 0.68 & 0.032 & 0.035 & 0.039 & 0.042 & 0.096 \\
\hline 0.76 & 0.035 & 0.038 & 0.042 & 0.045 & 0.090 \\
\hline 0.84 & 0.038 & 0.042 & 0.045 & 0.049 & 0.093 \\
\hline 0.92 & 0.042 & 0.046 & 0.050 & 0.054 & 0.060 \\
\hline 1.00 & 0.046 & 0.051 & 0.056 & 0.063 & 0.071 \\
\hline
\end{tabular}

Note: $\overline{\omega_{e}}$ is crankshaft relative angular velocity. 
Tabl.2. Matrix array of fuel consumption values $G_{n}$ at different load modes of operation MAN TGS 26.400

\begin{tabular}{|c|c|c|c|c|c|}
\hline \multirow{2}{*}{$\overline{\boldsymbol{\omega}_{\boldsymbol{e}}}$} & \multicolumn{5}{|c|}{$\overline{\boldsymbol{G}_{\boldsymbol{a}}}$-relative change in gross vehicle weight } \\
\cline { 2 - 6 } & $\mathbf{0 . 1 7 5}$ & $\mathbf{0 . 4 1 2}$ & $\mathbf{0 . 6 1 9}$ & $\mathbf{0 . 8 2 5}$ & $\mathbf{1 . 0 0 0}$ \\
\hline 0.19 & 0.137 & 0.155 & 0.198 & 0.259 & 0.275 \\
\hline 0.27 & 0.158 & 0.168 & 0.211 & 0.259 & 0.380 \\
\hline 0.35 & 0.181 & 0.181 & 0.224 & 0.268 & 0.507 \\
\hline 0.43 & 0.204 & 0.192 & 0.236 & 0.279 & 0.468 \\
\hline 0.51 & 0.228 & 0.204 & 0.249 & 0.292 & 0.452 \\
\hline 0.59 & 0.253 & 0.216 & 0.261 & 0.305 & 0.447 \\
\hline 0.68 & 0.279 & 0.228 & 0.273 & 0.319 & 0.613 \\
\hline 0.76 & 0.308 & 0.240 & 0.285 & 0.336 & 0.461 \\
\hline 0.84 & 0.347 & 0.251 & 0.299 & 0.359 & 0.481 \\
\hline 0.92 & 0.416 & 0.262 & 0.317 & 0.396 & 0.519 \\
\hline 1.00 & 0.569 & 0.275 & 0.350 & 0.469 & 0.398 \\
\hline
\end{tabular}

Table.3. Matrix array of engine torque values $M_{e}$ at different load modes of operation ISUZU NQR71

\begin{tabular}{|l|c|c|c|c|c|}
\hline \multirow{2}{*}{$\overline{\boldsymbol{\omega}}_{\boldsymbol{e}}$} & \multicolumn{5}{|c|}{$\overline{\boldsymbol{G}_{\boldsymbol{a}}}$-relative change in gross vehicle weight } \\
\cline { 2 - 6 } & $\mathbf{0 . 3 6 4}$ & $\mathbf{0 . 5 2 3}$ & $\mathbf{0 . 6 8 2}$ & $\mathbf{0 . 8 4 1}$ & $\mathbf{1 . 0 0 0}$ \\
\hline $\mathbf{0 . 1 9}$ & 39.77 & 55.52 & 71.27 & 87.03 & 255.04 \\
\hline $\mathbf{0 . 2 7}$ & 44.06 & 59.95 & 75.84 & 91.73 & 259.88 \\
\hline $\mathbf{0 . 3 5}$ & 49.88 & 65.96 & 82.03 & 98.11 & 266.45 \\
\hline $\mathbf{0 . 4 3}$ & 57.22 & 73.54 & 89.85 & 106.17 & 274.75 \\
\hline $\mathbf{0 . 5 1}$ & 66.09 & 82.70 & 99.30 & 115.91 & 284.77 \\
\hline $\mathbf{0 . 5 9}$ & 76.49 & 93.43 & 110.38 & 127.32 & 296.52 \\
\hline $\mathbf{0 . 6 8}$ & 88.42 & 105.75 & 123.08 & 140.40 & 300.48 \\
\hline $\mathbf{0 . 7 6}$ & 101.87 & 119.64 & 137.40 & 155.17 & 287.14 \\
\hline $\mathbf{0 . 8 4}$ & 116.86 & 135.11 & 153.36 & 171.60 & 285.03 \\
\hline $\mathbf{0 . 9 2}$ & 133.37 & 152.15 & 170.94 & 189.72 & 208.50 \\
\hline $\mathbf{1 . 0 0}$ & 151.40 & 170.77 & 190.14 & 209.51 & 228.88 \\
\hline
\end{tabular}

Table.4. Matrix array of engine torque values $M_{e}$ at different load modes of operation MAN TGS 26.400

\begin{tabular}{|c|c|c|c|c|c|}
\hline \multirow{2}{*}{$\overline{\boldsymbol{\omega}_{\boldsymbol{e}}}$} & \multicolumn{6}{|c|}{$\overline{\boldsymbol{G}_{\boldsymbol{a}}}-$ relative change in gross vehicle weight } \\
\cline { 2 - 6 } & $\mathbf{0 . 1 7 5}$ & $\mathbf{0 . 4 1 2}$ & $\mathbf{0 . 6 1 9}$ & $\mathbf{0 . 8 2 5}$ & $\mathbf{1 . 0 0 0}$ \\
\hline 0.19 & 389.48 & 475.57 & 692.69 & 909.82 & 953.46 \\
\hline 0.27 & 451.95 & 498.98 & 717.88 & 936.79 & 1267.83 \\
\hline 0.35 & 526.63 & 526.97 & 748.00 & 969.03 & 1581.98 \\
\hline 0.43 & 613.53 & 559.53 & 783.04 & 1006.54 & 1583.19 \\
\hline 0.51 & 712.63 & 596.67 & 823.00 & 1049.33 & 1584.58 \\
\hline 0.59 & 823.95 & 638.39 & 867.89 & 1097.39 & 1586.13 \\
\hline 0.68 & 947.48 & 684.68 & 917.70 & 1150.72 & 1900.48 \\
\hline 0.76 & 1083.23 & 735.55 & 972.44 & 1209.33 & 1589.75 \\
\hline 0.84 & 1231.18 & 791.00 & 1032.10 & 1273.21 & 1591.82 \\
\hline 0.92 & 1391.35 & 851.02 & 1096.69 & 1342.36 & 1594.05 \\
\hline 1.00 & 1563.73 & 915.62 & 1166.20 & 1416.78 & 1283.35 \\
\hline
\end{tabular}

Based on the data of the matrix arrays using the least squares method, the regression equations are determined $M_{e}=f\left(G_{n}\right)$ (Figure - 1). The resulting regression equations $M_{e}=f\left(G_{n}\right)$ show the correlation dependence of the engine torque $M_{e}$ on the fuel consumption $G_{n}$. 

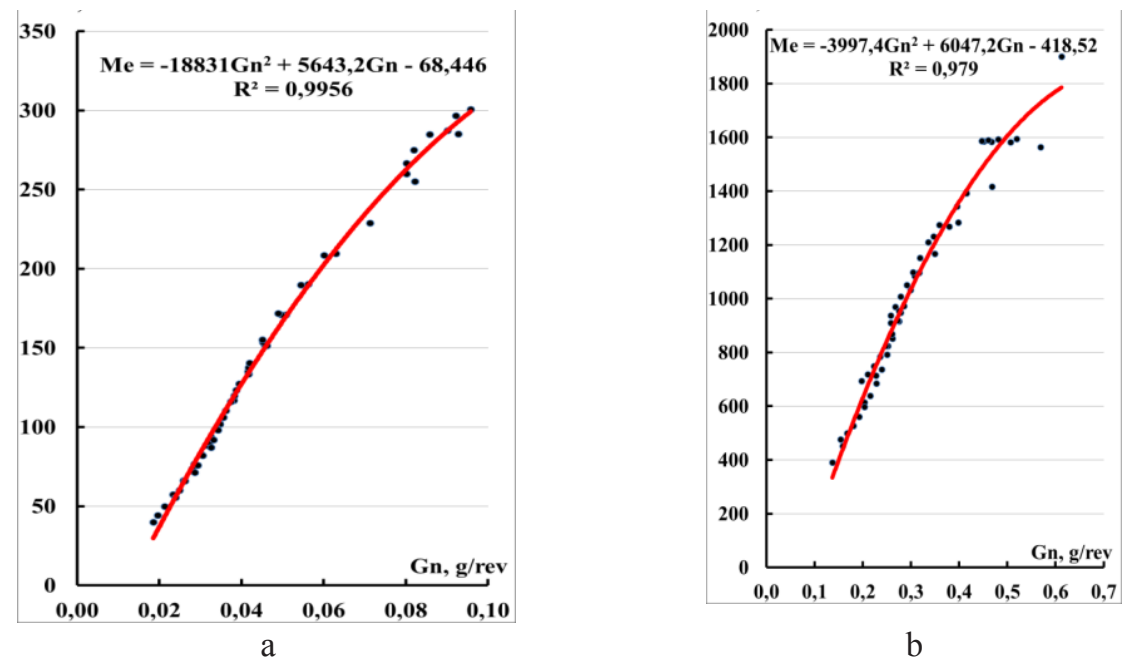

Fig.1. Regression equations $M_{e}=f\left(G_{n}\right)$ on the example of trucks:

a) ISUZU NQR71; b) MAN TGS 26.400

Correlation analysis of the obtained regression equations shows a high degree of dependence, the coefficient of determination $R^{2}$ makes up for ISUZU NQR71 - 0,9956 and MAN TGS $26.400-0.979$. In the course of the correlation analysis, linear and polynomial data approximations were considered. Linear correlation showed a high degree of dependence $M_{e}=f\left(G_{n}\right)$ (ISUZU NQR71 - 0,973, MAN TGS $26.400-0,959$ ). However, as the fuel consumption tends to infinity, the value of the regression equation also tends to infinity, which does not take into account the design features of the engine in terms of the maximum torque value.

The polynomial correlation dependence is determined by solving the system of equations, as a result of which the coefficients of the regression equation are revealed $M_{e}\left(G_{n}\right)=a G_{n}{ }^{2}+b G_{n}+c$.

Regression equation coefficients:

for truck ISUZU NQR71: $a=-18831 ; b=5643,2 ; c=-68,446$.

for truck MAN TGS 26.400: $\mathrm{a}=-3997,4 ; \mathrm{b}=6047,2 ; \mathrm{c}=-418,52$.

The difference between regression equations of a quadratic, cubic, or more character does not exceed $1 \%$.

To assess the reliability of the regression equations $M_{e}=f\left(G_{n}\right)$, the experimental data of the American laboratory «National Vehicle and Fuel Emissions Laboratory» and «National Center for Advanced Technology» (Figure 2) [19, 20] were used. 

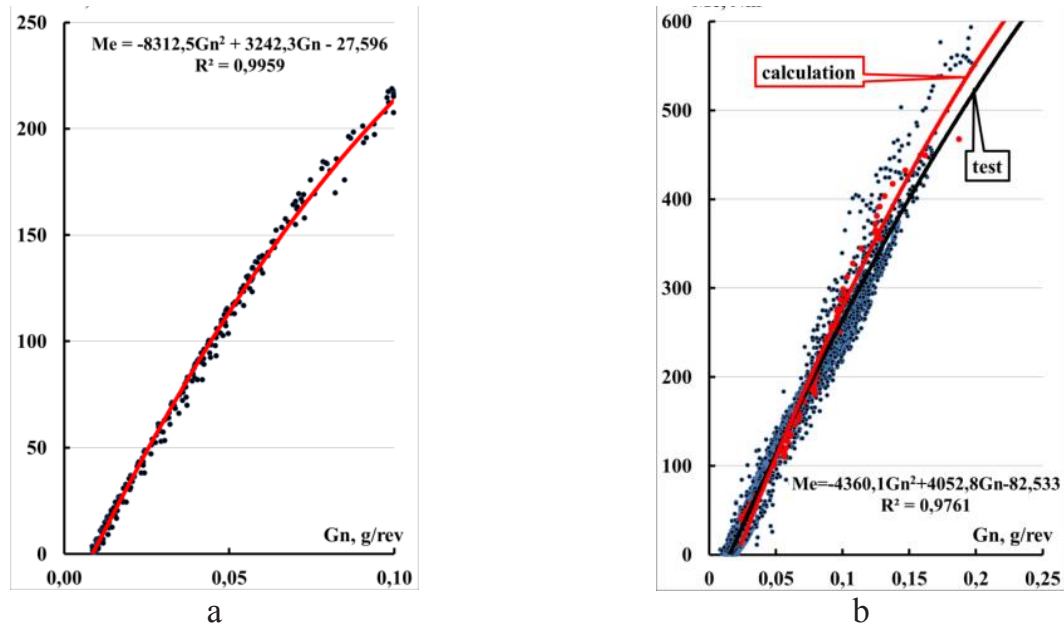

Fig. 2. Approbation of the results of the regression equation $M_{e}=f\left(G_{n}\right)$ with experimental data on the example of cars:

a) FORD 1.6 L EcoBoost; b) Mercedes E350 BlueTEC.

The vehicles are equipped with the Common Rail system. According to the US standard, the Mercedes E350 BlueTEC was tested on a US06 driving cycle, which indicates the functionality of the regression equation in vehicle acceleration modes, and the FORD 1.6L EcoBoost was tested on steady-state engine operating conditions. The calculated results of the regression equation and tests of the Mercedes E350 BlueTEC differ by almost $10 \%$ at high engine loads.

Based on the foregoing, it can be established that to determine the mechanical energy required to overcome the forces of resistance to movement in the traction mode; the main input data are $G_{T}, m_{a}, V_{a}, \omega_{e}, r_{k}$ - respectively, the hourly fuel consumption, the mass of the vehicle, the vehicle speed, the angular velocity of the crankshaft, the rolling radius of the driving wheels and the main technical characteristics of the given vehicle.

According to formula (7), $G_{T}$ is converted into a fuel consumption corresponding to one revolution of the crankshaft $G_{n}$ and using the regression equation $M_{e}=f\left(G_{n}\right)$, the engine torque is determined. However, to bring the torque $M_{e}$ to the driving wheels, to further determine $M_{k}$, it is required to determine the gear ratio of the transmission $U_{t r}$.

The transmission ratio is determined as follows

$$
U_{t r}=\frac{\omega_{e} r_{k}}{V_{a}}
$$

according to this, the torque applied to the driving wheels

$$
M_{k}=M_{e} U_{\text {тр }} \eta_{\text {тр }}=U_{\text {тр }} \eta_{\text {тр }}\left(a G_{n}^{2}+b G_{n}+c\right)
$$

where $a, b, c$ are regression equation coefficients, $M_{e}=f\left(G_{n}\right)$ displayed separately for each car model.

Based on the derived formulas, the mechanical energy of the vehicle in traction mode is determined by the following formula

$$
E_{A}=\int_{t_{i}}^{t_{f}} N_{k} d t=\int_{t_{i}}^{t_{f}} \omega_{e} \eta_{\mathrm{Tp}}\left(a G_{n}^{2}+b G_{n}+c\right) d t
$$


The revealed equation of the mechanical energy of the car is measured by the energy index $-J$.

\section{Conclusion}

The reliability of the results of the regression equation of the dependence of the engine torque on the fuel consumption $M_{e}=f\left(G_{n}\right)$ is $95-97 \%$, depending on the type and model of the car.

It was found that mechanical energy, in contrast to the current indicator of transport work $[t \cdot k m]$, varies in a wide range and has a hyperbolic character concerning the speed of movement and concerning the mass of the load and the coefficient of resistance of the road, it has linear patterns of change.

The proposed formula (13) takes into account the traction modes of the vehicle on the route, the resistance of the road, the aerodynamic parameters of the body and the mass of the vehicle together with the load, which together determine the real load on the structure in the transport mode under operating conditions.

The practical application of the research results will increase the efficiency of vehicle operation. By improving the monitoring system for the energy efficiency of a vehicle using on-board electronic systems, it will reduce the costs of technical operation and emissions on the environment and save energy resources.

\section{References}

1. Amir Izadi, Mohammad Nabipour \& Omid Titidezh, Cost Models and Cost Factors of Road Freight Transportation: A Literature Review and Model Structure, Fuzzy Information and Engineering, DOI: 10.1080/16168658.2019.1688956. (2020).

2. Bishop, J. D. K., Martin, N. P. D. and Boies, A. M. Quantifying the role of vehicle size, powertrain technology, activity and consumer behaviour on new uk passenger vehicle fleet energy use and emissions under different policy objectives. Applied Energy, 180, pp 196-212. (2016).

3. Carlan V, Sys C, Vanelslander T. Innovation in road freight transport: quantifying the environmental performance of operational cost-reducing practices. Sustainability, 11 (8). 2212. (2019).

4. Duan L, Tavasszy LA, Rezaei J. Freight service network design with heterogeneous preferences for transport time and reliability. Transp Res E Logist Transp Rev. (124), pp 1-12.(2019).

5. Gao, Y. and Checkel, M. D. Experimental measurement of on-road CO2 emission and fuel consumption functions. SAE Paper No. 2007-01-1610. (2007).

6. Guzzella, L.; Sciarretta, A. Vehicle Propulsion Systems. Introduction to Modeling and Optimization, Springer Verlag: Berlin, Germany, p 418. (2013).

7. Hong, M., Ouyang, M. and Shen, T. Torque-based optimal vehicle speed control. Int. J. Automotive Technology 12,(1), pp 45-49. (2011).

8. IEA, Policy Pathways: Improving the Fuel Economy of Road Vehicles-A Policy Package. International Energy Agency. (2012).

9. Kim, D.W., Yoon, J.W., Park, S. et al. Fuel consumption parameters for realizing and verifying fuel consumption prospect algorithm of vehicle driving route information system. Int.J Automot. Technol. (14), pp 955-964, https://doi.org/10.1007/s12239-013-0105-0. (2013).

10. Kropiwnicki, J., Kneba, Z. \& Ziółkowski, M. Test for assessing the energy efficiency of vehicles with internal combustion engines. Int.J Automot. Technol. 
(14), pp 479-487 https://doi.org/10.1007/s12239-013-0052-9. (2013).

11. Kropiwnicki, J. Identification of real vehicle operating conditions. FISITA 2010, World Automotive Cong., Budapest, F2010-G-004. (2010).

12. Liang, Z., Chen, L., Alam, M. S., Rezaei, S. Z., Stark, C., Xu, H. and Harrison, R. M. Comprehensive chemical characterization of lubricating oils used in modern vehicular engines utilizing GCXGC-TOFMS. Fuel, (220), pp 792-799. (2018).

13. Leung, D., Williams, D. Modelling of Motor Vehicle Fuel Consumption and Emissions Using a Power-Based Model. Environ Monit Assess (65), pp 21-29. https://doi.org/10.1023/A:1006498328936. (2000).

14. Mansour, C., Clodic, D. Optimized energy management control for the Toyota Hybrid System using dynamic programming on a predicted route with short computation time. Int.J Automot. Technol. (13), pp 309-324 https://doi.org/10.1007/s12239-012-0029-0. (2012).

15. Ping, Y., Long, W., Feng, L., Chen, L., Cui, J. and Gong, W. Investigation of evaporation and autoignition of isolated lubricating oil droplets in natural gas engine in-cylinder conditions. Fuel (235), pp 1172-1183. (2019).

16. Saboohi, Y. and Farzaneh, H. Model for developing an eco-driving strategy of a passenger vehicle based on the least fuel consumption. Applied Energy, (86), pp 1925-1938. (2009).

17. Sergio Camisón-Haba \& Jose A. Clemente-Almendros A global model for the estimation of transport costs, Economic Research-Ekonomska Istraživanja, 33 (1), pp 2075-2100, DOI: 10.1080/1331677X.2019.1584044. (2020)

18. Vanyeyev, S. M., Miroshnichenko, D. V., Rodymchenko, T. S., Protsenko, M., Smolenko, D. V. Data measuring system for torque measurement on running shafts based on a non-contact torsional dynamometer. Journal of Engineering Sciences, Vol. 6 (2), pp. 15-23, doi: 10.21272/jes.2019.6(2).e3. (2019).

19. 2013 Mercedes E350 BlueTEC Vehicle Diesel Fuel - Test Data Package. Version 2018-09. Ann Arbor, MI: US EPA, National Vehicle and Fuel Emissions Laboratory, National Center for Advanced Technology, (2018).

20. 2013 Ford 1.6L EcoBoost Engine Tier 2 Fuel - Test Data Package. Version 201810. Ann Arbor, MI: US EPA, National Vehicle and Fuel Emissions Laboratory, National Center for Advanced Technology, (2018). 